June 22-26, 2020, London, England

GT2020-16204

\title{
EFFICIENT STEADY AND UNSTEADY FLOW MODELING FOR ARBITRARILY MIS- STAGGERED BLADEROW UNDER INFLUENCE OF INLET DISTORTION
}

\author{
Hien M. Phan', Li He ${ }^{1}$ \\ ${ }^{1}$ Department of Engineering Science, University of Oxford, Oxford OX2 0ES, United Kingdom
}

\begin{abstract}
Accurate and efficient predictions of the steady and unsteady flow responses due to the blade-to-blade variation as well as due to the non-axisymmetric inlet distortion have been continually pursued. Computation of two problems concurrently has been rarely done in the past partly because of the need to perform whole annulus bladerow simulations, despite the advances in the current state-of-the-art methods with the phaseshift single passage simulations. The current work attempts to deal with this challenge by developing a new computational approach based on the principle of the multiscale method in the framework of a commercial solver (CFX). The methodology formulation relies on summation of the constituent source terms, each of which corresponds to a particular flow perturbation. The source term element corresponding to the blade-to-blade variation effect is linearly superimposed as in the classical Influence Coefficient Method. Only the relative positions between the reference blade and its neighbor matter in this method, thus enables an arbitrarily mis-staggered bladerow to be computed efficiently. In addition, the source term arisen due to the inlet distortion is calculated based on spatial Fourier transform. A key enabler is that the source term can be precomputed using a small set of identical blade passages. The source term is then propagated to different spatial and temporal locations depending on the combination of the mis-staggering pattern and the inlet distortion. The multiscale treatment makes it possible to predict a high-resolution flow field effects on the base coarse mesh as if the fine mesh is solved, while achieving a computational gain. The source term summation method proposed in the current work has been validated using a uniformly staggered bladerow, and an arbitrarily mis-staggered bladerow in a clean inflow condition as well as that subject to an inlet distortion.
\end{abstract}

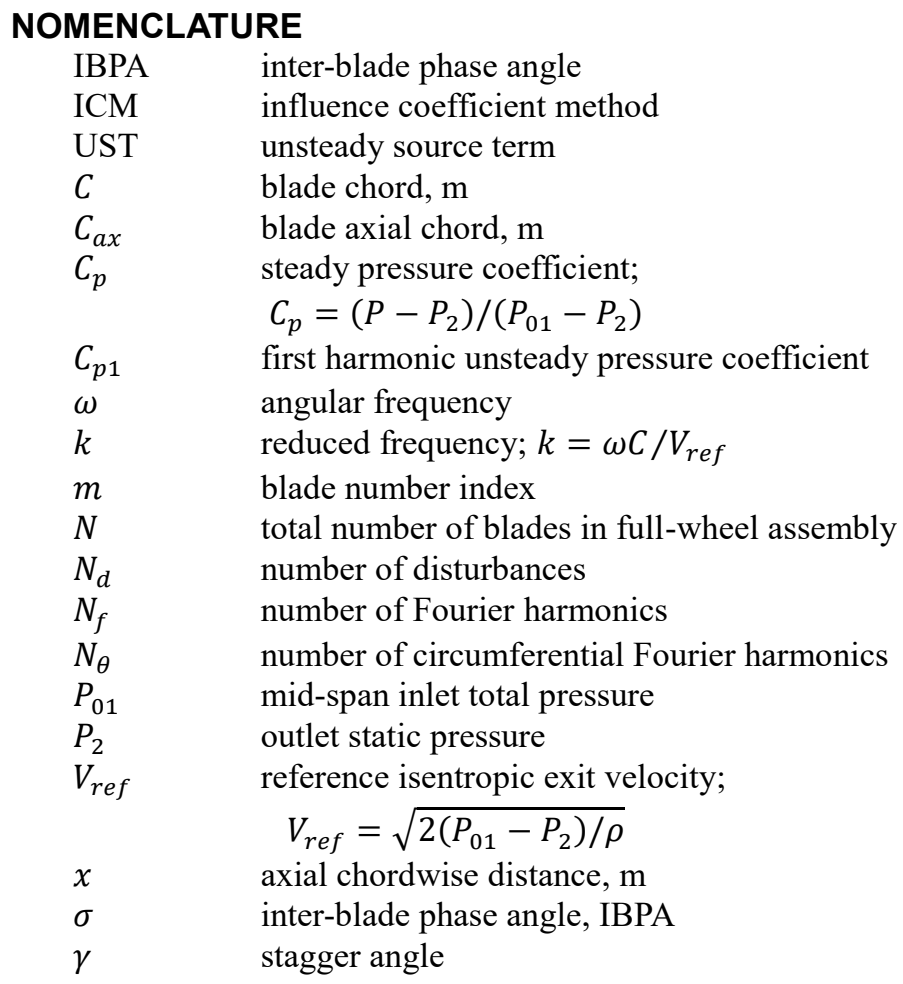

\section{INTRODUCTION}

The challenge to design an efficient and reliable gas turbine has been continually tackled by both the aviation and power generation industry. The development is driven not only by market demand for a low operating cost machine but also by increasingly strict regulations to reduce exhaust emissions and noise pollution. While doing so, the gas turbine manufacturer is also under a pressure to launch their latest technology with a fairly reasonable capital expenditure projection as well as the development time. In the last few decades, CFD simulation tools have been proven to be useful in the design and analysis cycle, 
leading to a much shorter product-to-market cycle and much cheaper development cost compared to that in the early days of the industry. Within the numerical simulation framework, the steady single-passage RANS solution is widely adopted under the assumption that all blades are identical. With the spatial and temporal periodicity assumption, the simulations can be carried out with well-established periodicity boundary conditions. In a few scenarios, the periodicity conditions can stretch for several blade pitches (i.e. the flow pattern repeats itself after an integer number of blade passages, dividing the whole annulus into what is known as nodal diameter). For some extreme cases, the pattern can have a wavelength of the whole circumference, which hinders the effectiveness of the classical direct periodicity simulations. In these cases, the current state-of-the-art numerical methodology is to adopt a phase-shifted periodicity. Erdos et al. [1] pioneered the direct store method, which has been superseded by more advanced approaches such as time-inclination [2], shape-correction [3], and chorochronic periodicity [4]. On the basis of the aforementioned approaches, it is now rather common to perform efficient unsteady flow modeling as a routine task using advanced methods such as Non-Linear Harmonic [5] and Harmonic Balance [6]. Extensions and applications of those methods are still an on-going topic of research [7-10]. A review of the use and history of Fourier method for turbomachinery applications can be found in Ref. [11].

The attention towards the effects of non-axisymmetric flow has been drawn by experts in turbomachinery $[12,13]$. The nonaxisymmetric flow field may arise from the blade-to-blade variation or from the external disturbances. The inherently stochastic behavior of blade-to-blade variations can trace their roots back to variations during manufacturing and assembly processes. Non-uniform flow field is also arisen as a result of external disturbances coming from upstream and downstream (e.g. wakes, gusts, potential fields).

The blade-to-blade variation may include but not limited to possible changes in various parameters such as the stagger angle, the leading and trailing edge shape, and the blade thickness and camber. Roberts et al. [14] tested a transonic compressor rotor with a varying chord length due to the leading edge blending and contouring during the component refurbishment. They found that the alternating blade configuration gave the best stall margin, although the stall margin varied by only $2 \%$ for all tested configurations. In terms of the efficiency, the alternating configuration performed the worst at part-speed. Montomoli et al. [15] found that fillet radius and tip gap uncertainties would lead to $60 \%$ variation in the overall mass-flow and $15 \%$ variation in the heat loading compared to the nominal conditions. Lu et al. [16] studied mis-staggering effects of a transonic fan blade running shape. They found that the whole-circumference uniformly staggered bladerow (1 nodal diameter pattern) would have the lowest efficiency reduction followed by the random mis-staggered pattern. The alternating passage divergence pattern, where each consecutive blade is mis-staggered in an opposite orientation, resulted in the highest efficiency reduction. Wilson et al. [17] showed that the stagger pattern change only significantly influenced the efficiency at the design point condition (peak efficiency). At the corrected mass flow lower or higher than that at the design point, the efficiency variation was much less significant. More closely related to aeroelasticity, various researchers have found that the aerodynamic detuning typically enhanced flutter stability [18-21].

On the other hand, the influence of inlet distortion has always been an extensive subject of research due to its detrimental effects on the stall margin $[22,23]$. With the current trend in the Boundary Layer Ingestion technology to improve the propulsive efficiency, the aerodynamic and aeroelastic response of the fan to inlet distortion has been received an increasing attention [24-27]. If blade shapes are assumed to be identical, the flow field subject to a circumferential inlet distortion can be computed using a single-passage solution with the current stateof-the-art based on the Fourier method [28-31].

Concurrent modeling of both aforementioned phenomena (i.e. blade-to-blade variation subject to inlet distortion) has been rarely studied in the past. Due to the inability to adopt the phaseshifted periodicity in this particular scenario, the simulation needs to be carried out in the whole annulus domain. As a result, the computation cost can be at least two or three orders of magnitude more expensive compared to the single-passage solution. Some efforts to perform such computations at a reduced cost have been made by some research groups [32,33]. However, these research efforts rely on either perturbations of the aerodynamic influence coefficient matrix or the dynamic stiffness matrix. Thus, only the blade force dynamic response can be captured.

With the background and modeling issues of interest as introduced so far, there is certainly a need to assess effects of the blade-to-blade variation with the presence of inlet distortion for the performance prediction and improvement. The computation cost must be lower than that predicted by a direct simulation of high-resolution whole-annulus assembly, whereas the accuracy must be comparable between the two computational results. In order to develop such a highly accurate method yet still efficient, we propose an approach based on the multiscale principle. The multiscale method is a source term-based approach that has been developed by solving different regimes with markedly different length and time scales [34-36]. The multiscale method so far has been typically used to deal with problems of many repetitive fine-scale element such as film and effusion cooling holes [37] as well as the additively manufactured pattern [38]. In the current framework, we adopt the multiscale method in a global manner, i.e. each passage domain has a particular global region in which the fine mesh is completely replaced by its coarse mesh counterpart. This approach would significantly reduce the total mesh count for the whole annulus bladerow compared to its direct fine mesh assembly, leading to an effective computational saving. The method of using two disparate mesh resolutions is herein referred in this context as the two-scale method. Apart from the computational gain from a reduced mesh count, the accuracy of the two-scale method compared to its direct fine mesh solution will be compared. Another aspect of modeling interest is the use of Influence Coefficient Method (ICM) with the source term-based approach. Typically the ICM method has 
been used to reconstruct the unsteady pressures of the tuned cascade based on linear superposition. In the current work, we propose the capability to perform such linear superposition with the source term as in the classical ICM method to reconstruct the whole flow field in the two-scale computations. This will be validated with the uniformly staggered as well as the arbitrarily mis-staggered bladerow.

\section{MODELING FORMULATIONS AND IMPLEMENTATION Source Term-Based Two-Scale Method Formulation}

The unsteady Navier-Stokes equations can be written in a semi-discrete form:

$$
\frac{\partial}{\partial t}(\boldsymbol{U})+R(\boldsymbol{U})=0
$$

The conservative flow variable $\boldsymbol{U}$ is a seven-element vector for a three-dimensional unsteady flow with two-equation turbulence model, $\boldsymbol{U}=[\rho \rho u \rho v \rho w \rho E \rho k \rho \omega]^{T} . R(\boldsymbol{U})$ is the lumped advection and diffusion terms.

We begin with the fine mesh simulation as in a conventional time-marching approach. If the simulation converges, the instantaneous governing equations are satisfied:

$$
\frac{\partial}{\partial t}\left(\boldsymbol{U}_{f}\right)+R_{f}\left(\boldsymbol{U}_{f}\right)=0
$$

Supposing the same flow domain is now discretized with a reduced spatial resolution. The poorly resolved but converged coarse mesh solution still satisfies the equations:

$$
\frac{\partial}{\partial t}\left(\boldsymbol{U}_{c}\right)+R_{c}\left(\boldsymbol{U}_{c}\right)=0
$$

The loss of solution accuracy when the mesh resolution reduces is obvious. Thus, in order to recover the fine mesh solution in the two-scale computation, the fine mesh solution needs to be projected to the coarse mesh discretization through volume-weighted averaging:

$$
\boldsymbol{U}_{f \rightarrow c}=\frac{1}{\Delta V_{c}} \sum \boldsymbol{U}_{f} \Delta V_{f}
$$

where the summation is taken for all the fine mesh cells of volume $\Delta V_{f}$ corresponding to a coarse mesh cell of $\Delta V_{c}$.

The volume-weighted averaging solution $\boldsymbol{U}_{f \rightarrow c}$ to be recovered in the two-scale simulation must also satisfy Equation 1. However, due to the difference between the volume-averaged solution $\boldsymbol{U}_{f \rightarrow c}$ and the coarse mesh solution $\boldsymbol{U}_{c}$, the projected solution $\boldsymbol{U}_{f \rightarrow c}$ does not satisfy the discretized governing equations on the coarse mesh:

$$
\frac{\partial}{\partial t}\left(\boldsymbol{U}_{f \rightarrow c}\right)+R_{c}\left(\boldsymbol{U}_{f \rightarrow c}\right) \neq 0
$$

Equation 5 can then only be balanced if a source term is introduced to the right-hand side of the equations [39]:

$$
\frac{\partial}{\partial t}\left(\boldsymbol{U}_{f \rightarrow c}\right)+R_{c}\left(\boldsymbol{U}_{f \rightarrow c}\right)=\boldsymbol{U S T}
$$

where $\boldsymbol{U S T}$ is the unsteady source term arisen due to the spatial resolution reduction. It is also a seven-element vector, where each entry is to balance its corresponding governing equations at anywhere in space and time.

The basic idea of the multiscale approach is to introduce an appropriate spatial-temporal source term to recover the projected fine mesh solution on the coarse mesh discretization of the twoscale computation as can be seen from Equation 6 .

In the present framework, the required unsteady source term is proposed to be a summation of its element to include effects due to multiple disturbances [40]. Thus, each individual constituent source term can be decoupled and pre-computed, which enables the required total source term to be estimated in an efficient manner:

$$
\boldsymbol{U S T _ { \text { total } }}=\overline{\boldsymbol{U S T}}+\sum_{i=1}^{N_{d}} \boldsymbol{U S \boldsymbol { T } _ { i }}
$$

where $\overline{\boldsymbol{U S T}}$ is the time-averaged source term. $\boldsymbol{U S \boldsymbol { S }} \boldsymbol{T}_{i}$ is the varying source term due to each disturbance $i . N_{d}$ is the number of disturbances that the flow field is subject to.

The source term due to each disturbance can be generally represented by a Fourier series of sufficiently high number of harmonics as in Equation 8. However, mostly the $1^{\text {st }}$ harmonic of the source term has been used in the current work. An assessment on the influence of high-harmonic terms will be conducted in a later part.

$$
\boldsymbol{U S \boldsymbol { T } _ { i }}=\sum_{n=1}^{N f}\left(A_{\boldsymbol{U}, i} \cos \left(n \omega_{i} t\right)+B_{U, i} \sin \left(n \omega_{i} t\right)\right)
$$

where $N_{f}$ is the number of Fourier harmonics retained of the considered disturbance; $\omega_{i}$ is the disturbance angular frequency.

In the current work, the disturbance can be arisen due to change in the blade stagger angle or due to the influence of external perturbation (e.g. inlet distortion). Calculation of each term in Equation 7 will be discussed in the next section.

\section{Steady/Time-Averaged Source Term Calculation}

Either a steady or time-averaged fine mesh solution can be chosen to perform volume-weighted averaging and transfer to the coarse mesh simulation. In the former case, the source term is denoted as $\boldsymbol{U} \boldsymbol{S} \boldsymbol{T}_{0}$. In the latter case, it is denoted as $\overline{\boldsymbol{U S T}}$. Note that these two source terms are not equal if the nonlinearity effect is sufficiently high due to the presence of the Reynolds stress term and the deterministic stress term after averaging.

The physical meaning of this term is to compensate the discrepancy between the steady/time-averaged fine mesh solution and the coarse mesh solution under no effects of blade motion and external disturbances. As the result, the flow field is symmetric and the direct periodicity or phase-shifted periodicity conditions can be applied to efficiently solve for the solution in a single-passage simulation. 
Given a steady/time-averaged fine mesh solution projected onto the coarse mesh discretization, the source term can be evaluated explicitly with the numerical discretization algorithm of the solver. However, it can also be possibly evaluated without knowing the detailed discretization process, which is particularly useful for a commercial solver as in the present case (CFX). The steady/time-averaged source term is computed in an iterative manner [37,52] and applied to CFX using an existing general source term model for each governing equation. The algorithm of the iteration process can be found in Appendix A.

Since previous works on the multiscale method only attempt to deal with a steady or time-averaged flow field, the method has been extended to deal with an unsteady flow as well as a grid perturbation in the current work. To the author knowledge, this is the first time such capability of the multiscale method can be implemented in the framework of a commercial solver (CFX). The specific unsteady source terms attributed to the misstaggering and inlet distortion effects will be discussed in more detail in the next sections. The process of the unsteady source term conversion to the frequency domain representation can be found in Appendix B.

\section{Staggering-Dependence Source Term Calculation}

Since Hanamura et al. [41] proposed the Influence Coefficient Method (ICM), it has become the most common method in getting equivalent tuned cascade data from experimental linear cascades and annular sector rigs with only one blade oscillating [42-51]. The classical use of the ICM is to calculate the $1^{\text {st }}$ harmonic unsteady pressure coefficient of the reference blade $C_{p 1}$ in a travelling wave mode by summing the unsteady pressure coefficients from the oscillating blade itself and its neighboring stationary blades, taking into account the constant inter-blade phase angle (IBPA):

$$
C_{p 1}=\sum_{m=-N / 2}^{+N / 2} C_{p 1}(m) e^{-i m \sigma}
$$

where $m$ is the blade number index. $N$ is the total number of blades in the whole annulus assembly. $\sigma$ is the constant IBPA defined as positive for a forward travelling wave mode.

In our proposed approach, the unsteady source term due to blade re-staggering will be linearly superimposed in the similar manner to the classical ICM:

$$
\boldsymbol{U S T}_{\text {stagger }}=\sum_{m=-N / 2}^{+N / 2} \boldsymbol{U S T}(m) e^{-i \sigma_{m}}
$$

where $\boldsymbol{U S T}(m)$ is the unsteady source term arisen in blade passage $m$ due to the motion of the reference blade $\mathrm{B}_{0} . \sigma_{m}$ is the relative IBPA between the blade $\mathrm{B}_{\mathrm{m}}$ and the reference blade $\mathrm{B}_{0}$.

At the special conditions when the IBPA is constant throughout the bladerow, Equation 10 becomes similar to the original form of the classical ICM. The physical significance of the proposed approach is that the instantaneous response of the reference blade can be reconstructed using the known relative positions between the reference blade and its neighbors.
To calculate the staggering-dependence source term, the direct fine mesh solution of the ICM-based cascade needs to be calculated first. Similar to the classical ICM approach, only the middle blade is re-staggered, while the adjacent blades are kept stationary. Figure 1 shows the schematic illustration of the method with two adjacent blades retained on each side of the central blade. A five-blade configuration is usually deemed to be sufficient due to the convergence of influence coefficients away from the central blade. At each instantaneous re-staggering movement of the central blade, the effects on itself and on the adjacent blades are recorded (see Figure 1). The ICM-based fine mesh solution is projected onto the coarse mesh, thus enables the calculation of the source term $\boldsymbol{U S T}(m)$ for each blade passage.

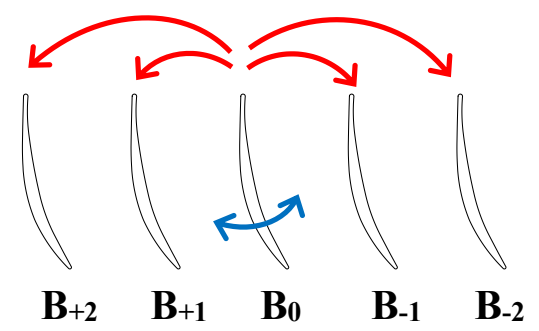

FIGURE 1: ILLUSTRATION OF THE SOURCE TERM INFLUENCE COEFFICIENT CALCULATION METHOD

Then in the whole annulus configuration, each blade can be re-staggered in any arbitrary way. The total source term applied to a reference passage $\boldsymbol{U} \boldsymbol{S} \boldsymbol{T}_{\text {stagger }}$ is a linear superposition of each individual passage's source term (Equation 10). Figure 2 shows the illustration of the source term superposition technique. In this example, only effects of the two closest adjacent blades on each side are taken into account, in accordance with the way the source term is calculated in the pre-calculation phase.

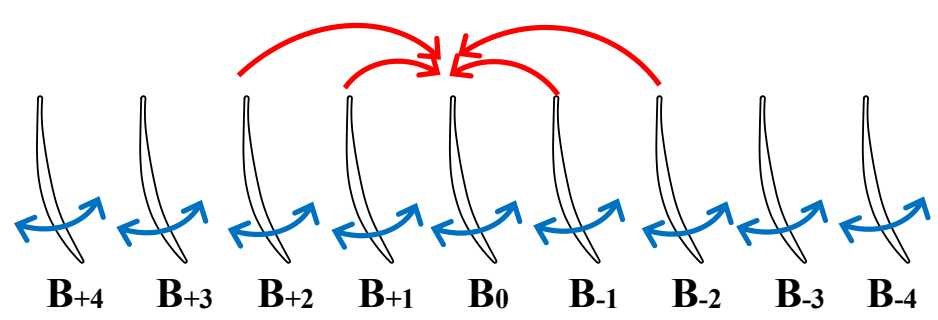

FIGURE 2: ILLUSTRATION OF THE SOURCE TERM LINEAR SUPERIMPOSITION METHOD IN AN ARBITRARILY MISSTAGGERED BLADEROW

Note that the uniformly staggered assembly does not necessarily mean each blade stagger angle must be exactly the same. Each blade can have a constant stagger angle change such that the whole bladerow is harmonically perturbed. This is then reduced to the conventional concept of travelling wave introduced by Lane [53] and can be solved efficiently using the common phase-shifted approach. The travelling wave tuned cascade will also be validated with the two-scale method and compared with the established tuned cascade simulation method. 


\section{Inlet Distortion-Dependence Source Term Calculation}

The inlet distortion simulation represents the situation in which the bladerow is subject to a circumferentially non-uniform flow field. Because no blade-to-blade variation is considered in the pre-calculation of the inlet distortion-dependence source term, it can be solved using the phase-shift single-passage simulation or solved directly using the whole annulus simulation. In the former case, the source term can be calculated as in the temporal Fourier method, whereas the spatial Fourier transform method can be used in the latter case. Figure 3 presents the whole annulus uniformly staggered bladerow subject to a non-uniform circumferential inlet stagnation pressure $P_{0}$ with a wavelength of a whole circumference.

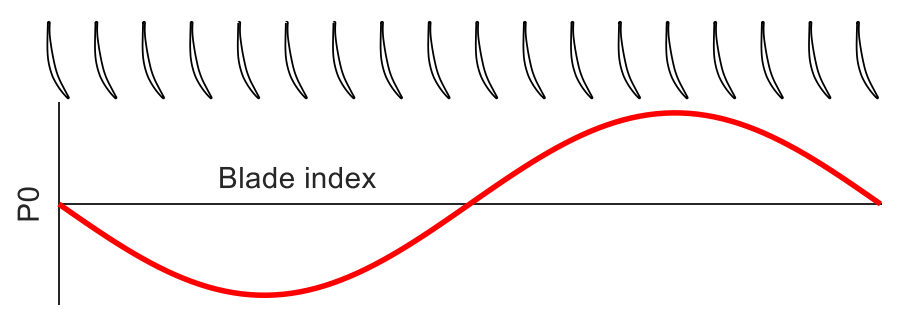

FIGURE 3: ILLUSTRATION OF THE SOURCE TERM METHOD WITH INLET DISTORTION

Performing discrete Fourier transform at any instantaneous time level, the inlet distortion-dependence source term can be calculated using the available circumferential positions:

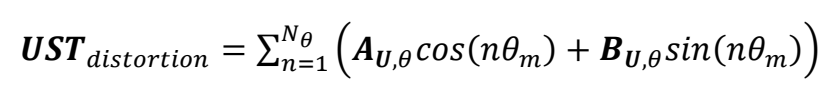

where $\theta_{m}=2 \pi(m-1) / N$. Note that $N_{\theta}$ is the number of retained spatial harmonics and $2 N_{\theta}+1 \leq N$.

\section{Practical Implementation}

The current methodology is implemented in the commercial solver CFX. The advection terms are discretized by a bounded high resolution scheme similar to the principles proposed by Barth and Jesperson [54]. The spatial derivatives in the diffusion terms are evaluated at the location of each integration point using the tri-linear shape functions. The transient terms are discretized by the second-order backward Euler scheme.

The inlet boundary conditions include total pressure, total temperature, and flow angle. The static atmospheric pressure is used at the outlet. The blades, hub, and casing surfaces are modelled as an adiabatic no-slip wall.

The central idea of the two-scale method is around the use of two disparate mesh resolutions. In the current implementation, the boundary layer region is chosen as the region of interest due to the typical requirement of sufficiently fine mesh to resolve the boundary layer on the blade surfaces. Figure 4 a shows the fine mesh resolution used in the direct fine mesh computation. Figure $4 \mathrm{~b}$ presents the coarse mesh resolution used in the two-scale method computation. The mesh has about 90k nodes for each 2D single passage fine mesh domain, whereas this is about $30 \mathrm{k}$ for each 2D single passage coarse mesh domain. In Figure 4, the mesh resolution near the blade surfaces can be clearly contrasted between the two domain discretization. The fine mesh in the boundary layer region $(\mathrm{y}+<1)$ allows the boundary layer to be resolved directly. However, the coarse mesh with a few elements in the boundary layer region would force the wall function model to take place and deteriorate the results.

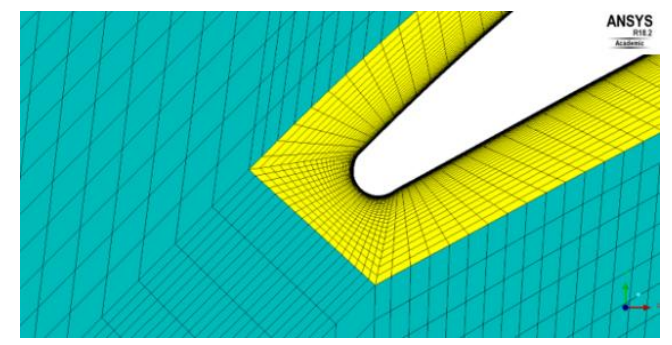

a) Fine mesh (in direct fine mesh computation)

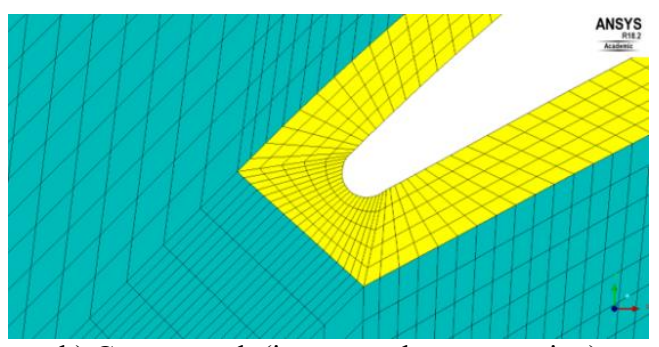

b) Coarse mesh (in two-scale computation)

FIGURE 4: MESH RESOLUTION IN THE BOUNDARY LAYER REGION OF a) DIRECT, AND b) TWO-SCALE SIMULATION

\section{TEST CASE}

The blade profile adopted in the present paper is of controldiffusion type, which is the representative of modern blading designs. Since the work of Elazar and Shreeve [55], this blade profile has been studied extensively both experimentally and numerically. The experimental results presented in the current study for validation purposes are acquired from the oscillating cascade test [56]. The experiment was conducted at a reduced Reynolds number $R e=1.95 \times 10^{5}$ compared to the original design Reynolds number $R e=7 \times 10^{5}$. At this lower Reynolds number, a laminar bubble separation was observed to form around mid-chord on the suction surface.

Table 1 shows a comparison between experimental and simulated operating conditions. Reynolds number $R e$ and exit isentropic velocity $V_{\text {ref }}$ are matched to a less than 5\% discrepancy from the experimental conditions.

Table 1 Experimental and Numerical Operating Conditions

\begin{tabular}{lcc}
\hline \hline Conditions & Experimental & Numerical \\
\hline $\begin{array}{l}R e \text { (based on blade chord } \\
\text { and exit velocity) } \times 10^{5}\end{array}$ & 1.95 & 1.967 \\
$\begin{array}{l}\text { Exit isentropic velocity } \\
\mathrm{ms}^{-1}\end{array}$ & 19.5 & 20.4 \\
\hline \hline
\end{tabular}




\section{VALIDATION OF UNIFORMLY STAGGERED CASCADE} Validation of Steady/Time-Averaged Source Term

The laminar bubble separation is reported to appear on the compressor blade suction surface in the experiment [56] at a low Reynolds number testing condition. High-fidelity models such as LES [57] have been shown to be effective in capturing the formation of laminar separation bubble and the associated transition. In the previous computational study [58], it was shown that using the two-equation $\gamma-\theta$ transition correlation coupled with the RANS SST model [59] is also able to predict the formation of separation bubble. Figure 5 compares the experimental steady pressure distribution at mid-span to that predicted by the fine mesh solution with different turbulence models, confirming the previous findings.

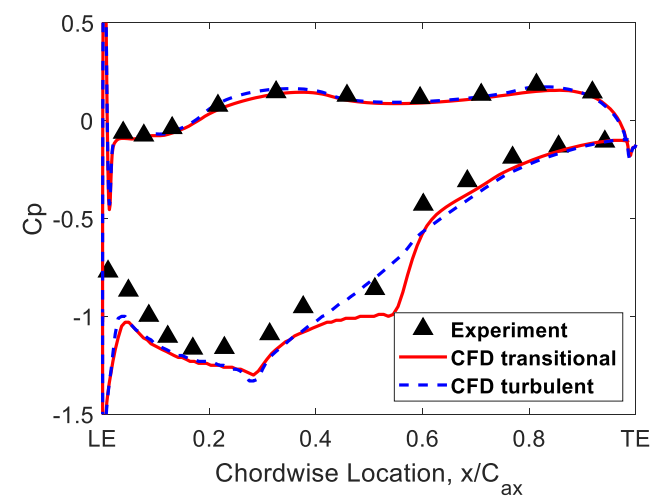

FIGURE 5: MID-SPAN STEADY PRESSURE DISTRIBUTION

The ability to calculate the steady source term and use it in the two-scale simulation to recover the fine mesh solution needs to be assessed. The total source term now only includes the steady component:

$$
\boldsymbol{U S T _ { \text { total } }}=\boldsymbol{U S T _ { 0 }}
$$

Figure 6a shows the comparison of mid-span steady pressure distribution between the direct fine mesh solution and the two-scale method with the fully turbulent model, whereas Figure $6 \mathrm{~b}$ presents the same comparison with the transitional model. For both turbulence models, the two-scale method shows excellent agreement with the fine mesh. For fully turbulent solution in Figure 6a, the mesh resolution does not take an important role. The coarse mesh solution mildly deviates from the fine mesh solution, with the largest difference in the front part of the suction surface. In contrast, mesh resolution plays a pivotal role in the prediction of transitional flow. From Figure 6b, the suction surface pressure distribution is distinctively different between the fine mesh and coarse mesh solution.

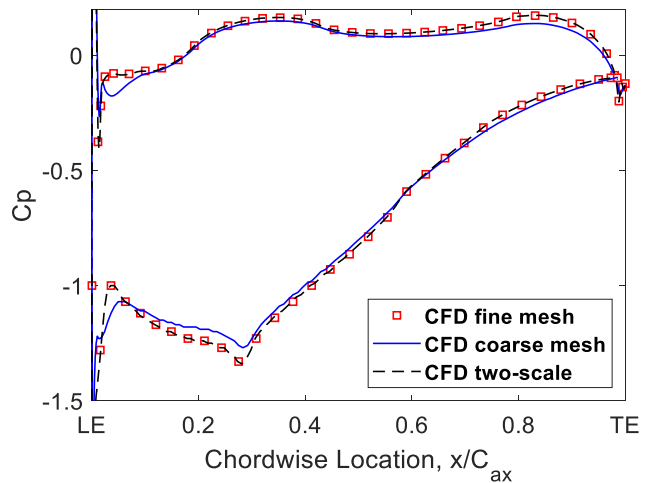

a) Fully turbulent model

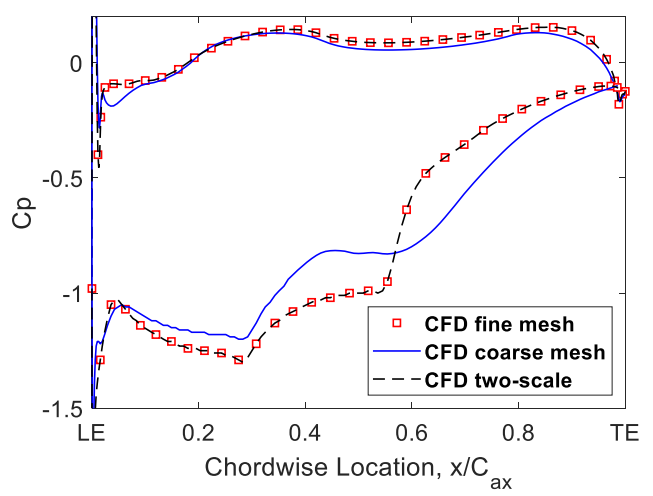

b) Transitional model

FIGURE 6: MID-SPAN STEADY PRESSURE DISTRIBUTION OF DIFFERENT CONFIGURATIONS WITH: a) FULLY TURBULENT AND b) TRANSITIONAL MODELS

The axial velocity contours between the fine mesh and coarse mesh solution with transitional model are presented in Figure 7. While fine mesh solution predicts a rather small separation bubble, the coarse mesh solution predicts a much bigger separation bubble and a more downstream transition onset. This is in agreement with the observed pressure distribution in Figure $6 \mathrm{~b}$ and in line with the requirement of sufficient mesh resolution by the $\gamma-\theta$ transitional model [59].

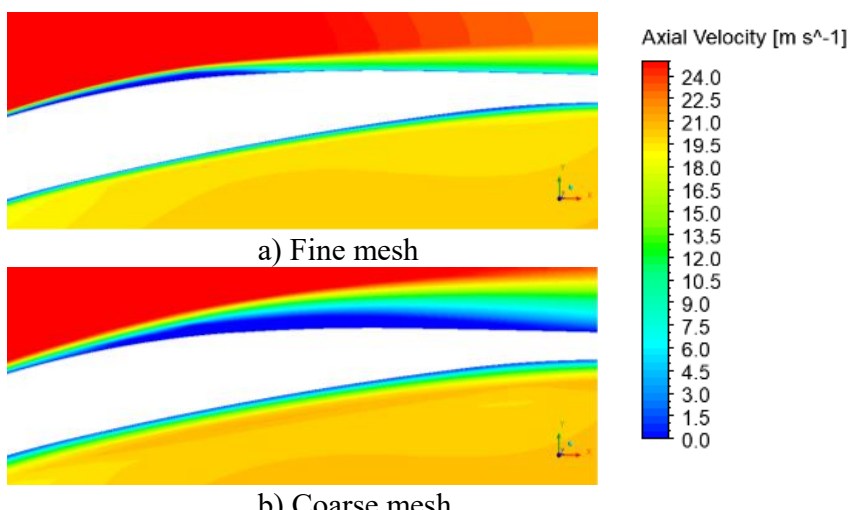

FIGURE 7: AXIAL VELOCITY CONTOUR OF DIFFERENT CONFIGURATIONS WITH TRANSITIONAL MODEL 


\section{Validation of Source Term Superimposition}

The linear superposition validity as in the classical ICM has been studied experimentally and numerically extensively and will not be a subject of interest of the current work. In the current implementation, we propose an approach to use the ICM to perform linear superimposition on the source term in an attempt to reconstruct a flow field of an arbitrarily mis-staggered bladerow. Because this is the first time such approach is used, validation works need to be done. Firstly, the two-scale solutions of finite-cascade ICM will be evaluated. The source term $\boldsymbol{U S T}(m)$ for each blade $m$ is reconstructed based on the desired maximum number of harmonics $N_{f}$ :

$$
\boldsymbol{U S T}(m)=\sum_{n=1}^{N f}\left(A_{\boldsymbol{U}, m} \cos \left(n \omega_{i} t\right)+B_{\boldsymbol{U}, m} \sin \left(n \omega_{i} t\right)\right)
$$

A rather low oscillating frequency for the torsional mode is chosen to illustrate a strong dependency of aerodynamic damping on the mesh resolution, which will be discussed more in detail later. Another modeling interest is the assessment on the number of harmonics of the source term. Thus, a transitional model is adopted in this part to compare the $1^{\text {st }}$ and $2^{\text {nd }}$ harmonic unsteady flow responses.

Figure 8 presents the overall damping curve for different configurations at the oscillating reduced frequency $k=0.3$. A drastic difference between the predictions of fine mesh and coarse mesh solution can clearly be observed. The coarse mesh configuration undergoes aeroelastic instability for the majority of IBPA. Although not presented here, the strong dependency of flutter susceptibility on the mesh resolution has been confirmed with a fully coupled fluid-structure interaction model. On the other hand, two-scale solutions greatly improve aerodamping predictions for all IBPA. With the use of $2^{\text {nd }}$ harmonic source term, the aero-damping prediction does not change. This behaviour will be examined more closely with the tuned cascade configuration.

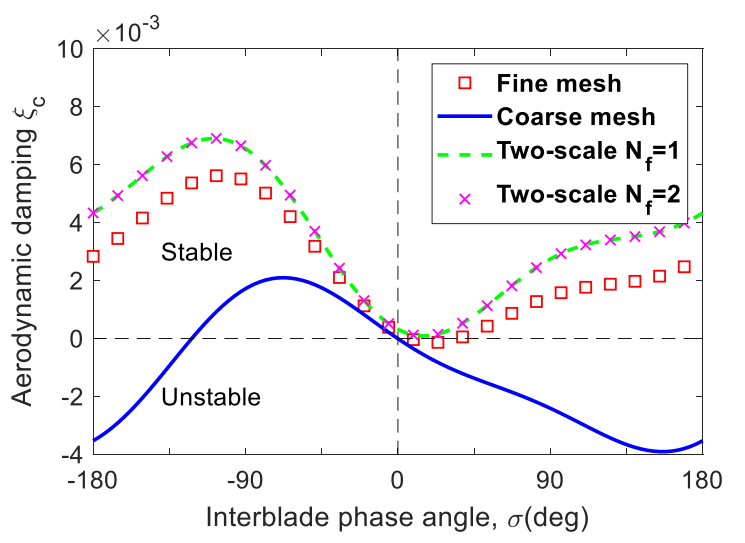

FIGURE 8: OVERALL AERODYNAMIC DAMPING OF DIFFERENT CONFIGURATIONS
Next, the tuned cascade is considered, such that all blades are uniformly staggered with a constant IBPA. The total source term applicable to a reference blade passage now has the form:

$$
\boldsymbol{U S T}_{\text {total }}=\overline{\boldsymbol{U S T}}+\sum_{m=-2}^{+2} \boldsymbol{U S T}(m) e^{-i m \sigma}
$$

The total source term applied into each passage is thus constant with a phase shift equal to the IBPA. Figure 9 presents the $1^{\text {st }}$ harmonic response of the unsteady pressures at a constant IBPA $\sigma=180^{\circ}$. From Figure 9a, the suction surface shows the highest discrepancy among investigated configurations. The coarse mesh predicts an opposite trend of sign compared to that predicted by the fine mesh. This is in agreement with the different aeroelastic stability trend observed in Figure 8 at $\sigma=$ $180^{\circ}$. On the other hand, the two-scale solution with $2^{\text {nd }}$ harmonic source term $\left(N_{f}=2\right)$ is almost identical to that with only the $1^{\text {st }}$ harmonic source term $\left(N_{f}=1\right)$.

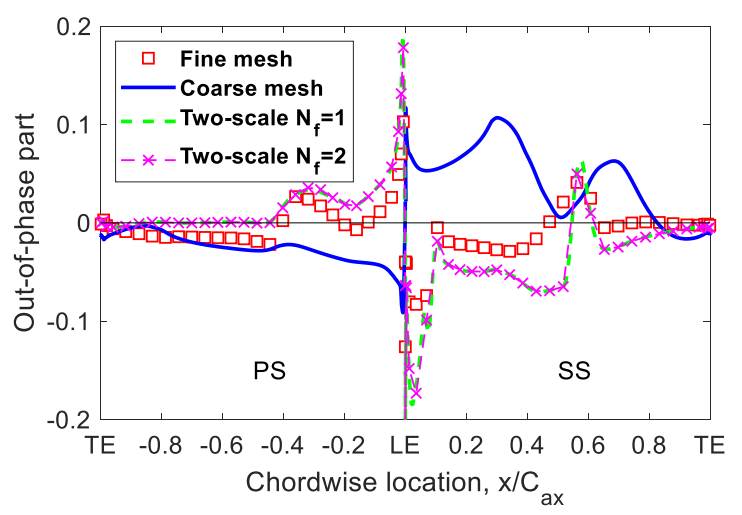

a) Out-of-phase part

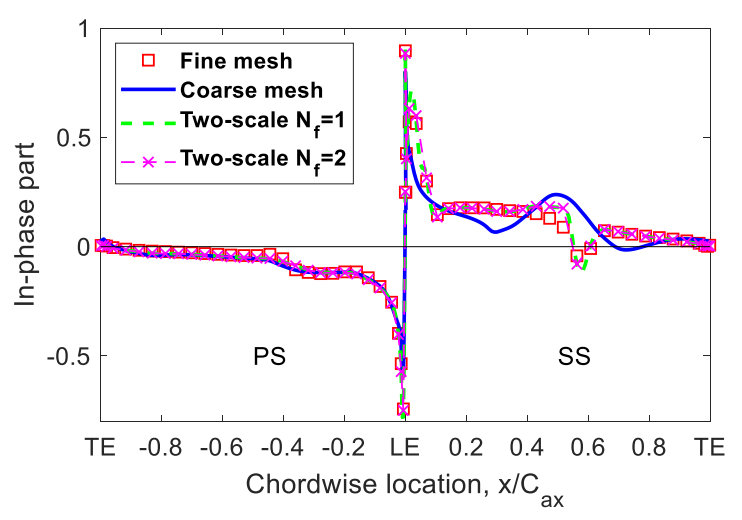

b) In-phase part

FIGURE 9: $1^{\text {st }}$ HARMONIC COMPONENTS OF DIFFERENT CONFIGURATIONS AT $\sigma=180^{\circ}$

Figure 10 presents the $2^{\text {nd }}$ harmonic response of the unsteady pressures at a constant IBPA $\sigma=180^{\circ}$. Similarly to what observed in the $1^{\text {st }}$ harmonic response (Figure 9), the suction surface is more sensitive to mesh resolution compared to the pressure surface. The two-scale solution with only the $1^{\text {st }}$ harmonic source term $\left(N_{f}=1\right)$ already shows an improved 
prediction in $2^{\text {nd }}$ harmonic response. With the addition of $2^{\text {nd }}$ harmonic source term $\left(N_{f}=2\right)$, the $2^{\text {nd }}$ harmonic response comparable to that of the fine mesh is fully recovered by the twoscale solution. However, it can be shown that high-harmonic unsteady pressures do not contribute to the aerodamping, which is also evidenced from the aerodamping curve (Figure 8). In addition, the investigated flow field is predominantly linear even with the separation bubble such that the high-harmonic terms do not significantly influence the fundamental harmonic term. Thus, it can be concluded that the use of $1^{\text {st }}$ harmonic source term is sufficient for aerodamping calculation, at least for this test case. If one wish to include high-harmonic effects, the high harmonic source terms might be used for an improved prediction.

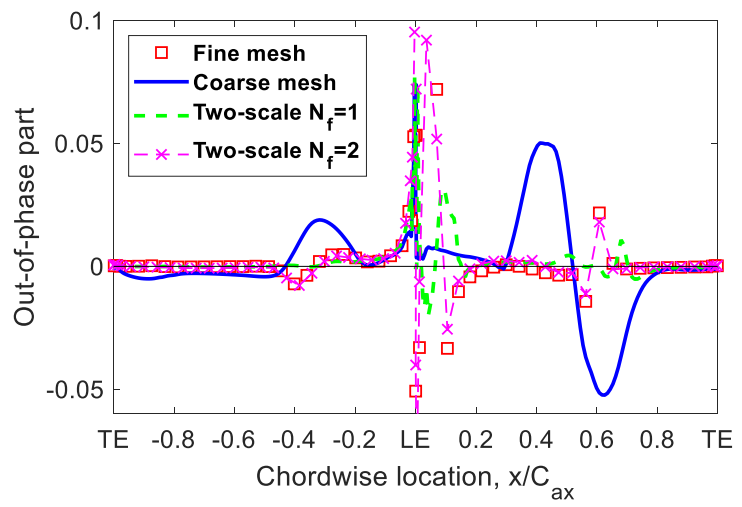

a) Out-of-phase part

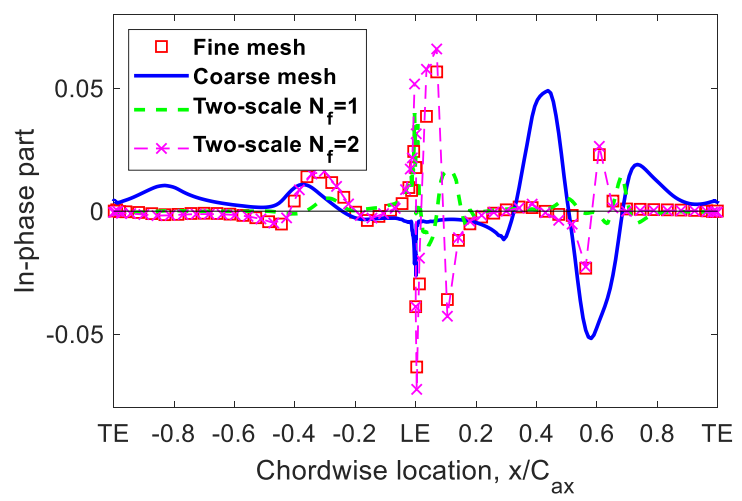

b) In-phase part

\section{COMPUTATIONAL EXAMPLES}

Arbitrarily Mis-Staggered Bladerow under Clean Inflow Condition

In this example, the compressor bladerow comprised of 18 blades is arbitrarily mis-staggered from the nominal position by a random pattern. Figure 11 presents the mis-staggering pattern for each individual blade. The nominal stagger angle for the uniform bladerow is 14.2 degrees. Each blade is re-staggered randomly within the maximum range of \pm 1 degrees deviated from the nominal position. The amplitude of mis-staggering is within the typical range of that used in the literature [16,17]. Figure 12 shows the schematic illustration of the mis-staggering pattern in the whole-annulus bladerow with an amplification factor of 10 to emphasize the random difference between the mis-staggered blades and their uniform counterpart.

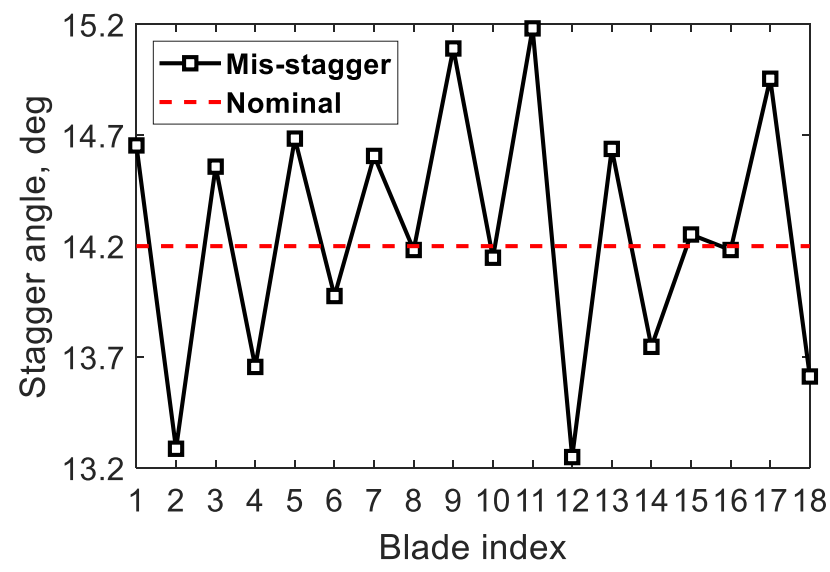

FIGURE 11: STAGGER ANGLE DISTRIBUTION IN THE ARBITRARILY MIS-STAGGERED BLADEROW

The total source term used in the two-scale method now has two constituent terms as shown in Equation 15. The first term is the averaged source term, while the second term is associated with the change in stagger angle. The second term is evaluated using the source term superimposition method described in the method formulation section for an arbitrarily mis-staggered assembly.

$$
\boldsymbol{U S T _ { \text { total } }}=\overline{\boldsymbol{U S T}}+\boldsymbol{U S} \boldsymbol{T}_{\text {stagger }}
$$

FIGURE 10: $2^{\text {nd }} H A R M O N I C$ COMPONENTS OF DIFFERENT CONFIGURATIONS AT $\sigma=180^{\circ}$

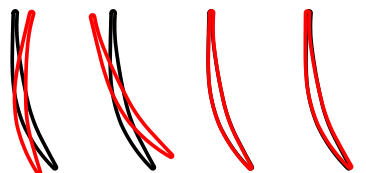

B18
$\mathbf{B}_{17} \mathbf{B}_{16}$

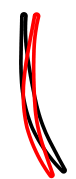

B15

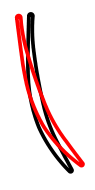

$\mathrm{B}_{13}$

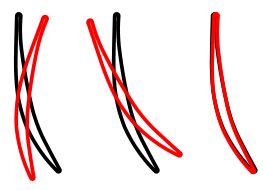

$B_{12} B_{11} \quad B_{10}$

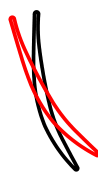

B9
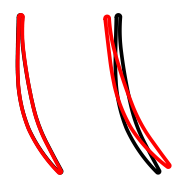

B8 $\quad$ B $7_{7}$

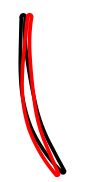

B6

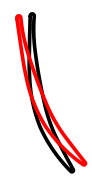

B5

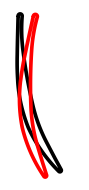

$\mathrm{B}_{4} \quad \mathrm{~B}_{3}$

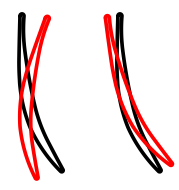

B $_{2}$ B1 $_{1}$

FIGURE 12: ARBITRARILY MIS-STAGGERED BLADEROW PATTERN ( - UNIFORMLY-STAGGERED, — MIS-STAGGERED), AMPLIFICATION FACTOR OF 10 
Figure 13 presents the steady lift force generated by all blades in the arbitrarily mis-staggered bladerow by simulations with different mesh resolution compared to that predicted by the two-scale method. The lift force for the uniform bladerow is also plotted to study the influence of stagger angle variation itself on the aerodynamics quantity of interest. The steady blade force is normalized by the isentropic exit dynamic head and the blade chord length.

$$
F=\frac{\int_{A} p d A}{\left(P_{01}-P_{2}\right) \times C^{2}}
$$

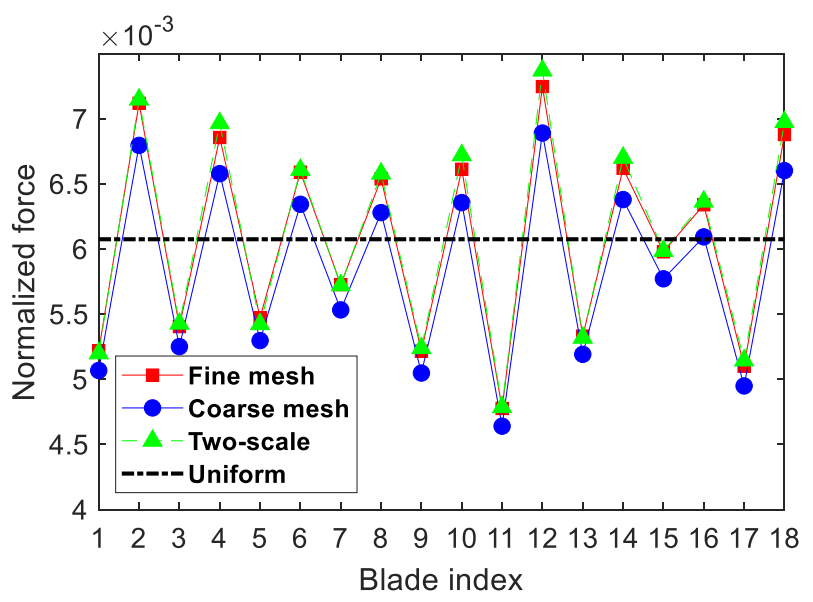

FIGURE 13: STEADY LIFT FORCE DISTRIBUTION IN THE ARBITRARILY MIS-STAGGERED BLADEROW

Each individual blade lift force is seen to diverge from their nominal value in the uniform bladerow. Their alternating fluctuation distributions from the nominal values can be attributed to the near-alternating stagger variation pattern (see Figure 11 and 12), which suggests that the influence of on-itself component is dominant. Thus, the change in steady lift force of a reference blade can be easily related to the effects of quasisteady change in incidence angle of itself. When the stagger angle increases (e.g. Blade 9, Blade 11), the blade is subject to a negative incidence leading to a lower lift force. Vice versa, when the stagger angle decreases (e.g. Blade 4, Blade 12), the blade is subject to a positive incidence leading to a higher lift force. Another interesting point can be made based on the observation of those blades with small deviation from the nominal position (e.g. Blade 10, Blade 15, Blade 16). Although the difference between their relative stagger angles with the nominal position is rather small (less than $0.4 \%$ ), their blade forces vary much more significantly (e.g. up to $9 \%$ for Blade 10). Blade 10 and Blade 15 also have two contrasting variation trends compared to their counterpart in the uniform bladerow. This finding confirms that the influence of a mis-staggered blade can propagate throughout the bladerow and affect their neighbors. Thus, it is important that sufficient neighboring blades have to be taken into account to reconstruct the response of the reference blade.
Although the maximum mis-staggering amplitude is only 1 degrees, the computation of mis-staggered bladerow reveals that the individual blade lift force can be drastically increased or reduced. For example, Blade 11 reduces $21.4 \%$ of its blade force compared to the uniform bladerow, while Blade 12 increases by $19.3 \%$. The remaining blades have their increase or reduction percentage fluctuated in the range $\pm 10-15 \%$.

Regarding the main interest of the current study on the accuracy of the proposed two-scale method, it can be seen that the use of two-scale method greatly improves the prediction accuracy of the direct coarse mesh solution. The solution of twoscale method usually differs from the direct fine mesh solution by less than $1 \%$ in the current computational example. Thus, the applicability of the source term superimposition method has been validated to be suitable for an arbitrarily mis-staggered bladerow subject to the clean inflow condition.

\section{Uniformly Staggered Bladerow under Inlet Distortion Quasi-Steady Rotating Inlet Distortion}

In this example, the compressor bladerow with uniform stagger angle distribution is subject to the stagnation pressure inlet distortion with the wavelength equal to the bladerow circumference. Equation 17 shows the formula for the inlet stagnation pressure distortion:

$$
P_{01}=P_{01, \text { uniform }}+\Delta P_{01} \sin \left(\omega t+\theta_{i}\right)
$$

where $P_{01, \text { uniform }}$ is the inlet total pressure at clean inflow condition. $\Delta P_{01}$ is the amplitude of the distortion perturbation, which is taken to be equal to $30 \%$ of the inlet stagnation pressure at clean inflow condition. $\theta_{i}$ is the relative phase angle between the $\mathrm{i}^{\text {th }}$ and the first pitchwise grid line.

The total source term used in the two-scale method now has two constituent terms as shown in Equation 18. The first term is the averaged source term, while the second term is associated with the change in inlet stagnation pressure due to inlet distortion. The second term is evaluated using the spatial Fourier transform method described in the method formulation section.

$$
\boldsymbol{U S} \boldsymbol{T}_{\text {total }}=\overline{\boldsymbol{U S T}}+\boldsymbol{U S} \boldsymbol{T}_{\text {distortion }}
$$

Figure 14 shows the instantaneous lift force evolution of the reference blade during one passing period of the inlet distortion. Because the bladerow is uniformly staggered, all blades are subject to the same force with a constant phase shift. It is observed in this case that the blade force can change drastically by $\pm 30 \%$ the value of its nominal force in the clean inflow condition. Thus, the induced dynamic stress arisen will be significantly affect the blade durability during its service life, possibly leading to a premature failure with High Cycle Fatigue if no counter-measure would be taken. On the other hand, it is noted that the predicted averaged blade force during the inlet distortion period is similar to that predicted earlier by the computation with clean inflow condition. This finding suggests that the non-linearity in the computed case is low, even when 
subject to a large disturbance amplitude of $30 \%$ of the inlet stagnation pressure at clean inflow condition. Under the influence of the inlet distortion, the two-scale method still shows its applicability to improve the prediction accuracy using a coarse mesh computation to less than $1 \%$ compared to the direct fine mesh solution.

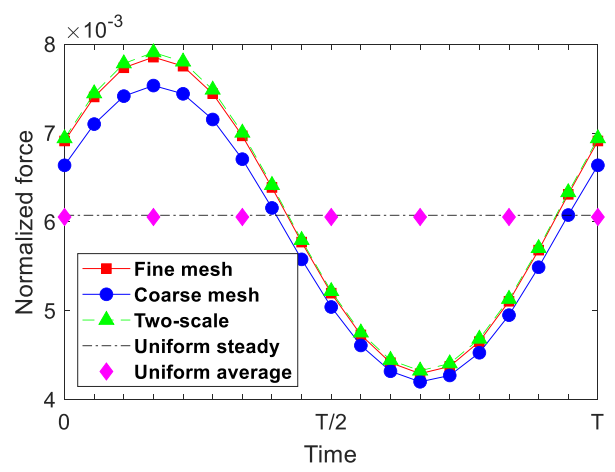

FIGURE 14: UNSTEADY LIFT FORCE EVOLUTION DURING ONE PERIOD OF QUASI-STEADY INLET DISTORTION IN THE UNIFORMLY-STAGGERED BLADEROW

\section{$\underline{\text { Unsteady Rotating Inlet Distortion }}$}

Here the inlet distortion is moved with a high reduced frequency $k=0.5$ calculated based on the reference isentropic outlet velocity $V_{\text {ref }}$ in the clean inflow condition. This is the representative case of a rotor bladerow subject to the inlet distortion. The total source term used in this example is still in the form of Equation 18. However, due to a highly unsteady effect, the temporal term $\frac{\partial}{\partial t}(\boldsymbol{U})$ has a bigger influence in the governing equations (see Equation 1). In contrast, if the flow can be regarded as steady or quasi-steady, the temporal term will vanish and the governing equations reduce to:

$$
R(\boldsymbol{U})=0
$$

Since this is the first time the multiscale method has been extended to consider the unsteady flow effects in the framework of a commercial solver, the capability to calculate such term needs to be validated. Figure 15 shows the instantaneous lift force evolution of the reference blade during one passing period of the inlet distortion with high reduced frequency $k=0.5$.

It can be observed in this case that the peak-to-peak force during one period is smaller compared to the case with quasisteady inlet distortion (Figure 15 vs Figure 14). The maximum unsteady force amplitude is reduced to within the range $\pm 5 \%$ the value of its nominal force in the clean inflow condition. Note that the unsteady inlet distortion amplitude is still comparable to the quasi-steady inlet distortion case (30\% amplitude of clean inflow stagnation pressure). Under the high frequency inlet distortion, the distortion passes through the compressor bladerow with the attenuated distortion strength. In the literature, this phenomena is known as stagnation pressure attenuation when the distortion pattern travels downstream the compressor bladerow [24,60,61].
On the other hand, the high similarity between the steady and time-averaged blade force confirms the predominant linearity of the problem, even with the high reduced frequency and the high distortion amplitude. Moreover, the two-scale method still shows its capability to improve the prediction accuracy using a coarse mesh computation to less than $1 \%$ compared to the direct fine mesh solution.

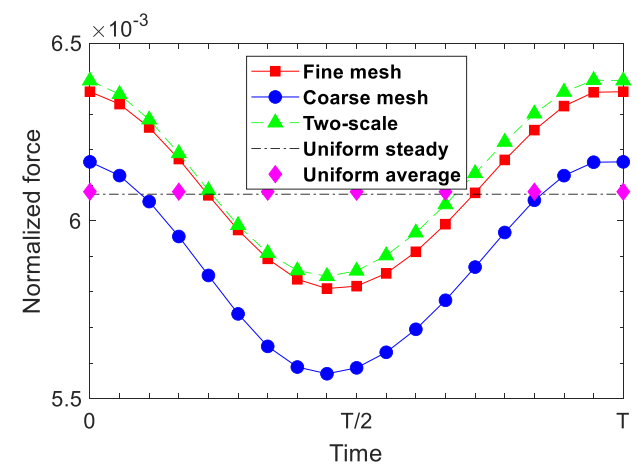

FIGURE 15: UNSTEADY LIFT FORCE EVOLUTION DURING ONE PERIOD OF INLET DISTORTION IN THE UNIFORMLYSTAGGERED BLADEROW AT $k=0.5$

\section{Arbitrarily Mis-Staggered Bladerow under Inlet Distortion}

In this example, the arbitrarily mis-staggered compressor bladerow is subject to the rotating inlet distortion with the wavelength equal to the bladerow circumference. The misstaggering pattern is the same as that used in the previous example (see Figure 11 and 12). The inlet stagnation pressure distortion formula is also similar to the previous examples (see Equation 16).

The total source term used in the two-scale method now has three constituent terms as shown in Equation 20. The first term is the averaged source term, the second term is related to the change in stagger angle, and the third term is associated with the change in inlet stagnation pressure.

$$
\boldsymbol{U S} \boldsymbol{T}_{\text {total }}=\overline{\boldsymbol{U S T}}+\boldsymbol{U S} \boldsymbol{T}_{\text {stagger }}+\boldsymbol{U S} \boldsymbol{T}_{\text {distortion }}
$$

Figure 16 shows the instantaneous lift force evolution of Blade 11 and Blade 12 in the mis-staggered bladerow during one passing period of the inlet distortion with high reduced frequency $k=0.5$. It is observed that the time-averaged blade forces in the mis-staggered bladerow are markedly different from that in the uniformly staggered bladerow. Two consecutive Blade 11 and Blade 12 even show a qualitatively different trend in the timeaveraged force. Although mis-staggering effect induces a reduction in the time-averaged blade force in Blade 11, there is an increase in the time-averaged blade force in Blade 12 due to mis-staggering. It has been confirmed from the previous computational examples that the nonlinearity in the currently investigated bladerow is small, thus we would expect a slight difference between the steady and time-averaged flow 
prediction. Recall the distribution of blade forces in the misstaggered bladerow at the steady flow environment (see Figure 13), it is clear that the steady blade force of Blade 11 and Blade 12 also show the same trend in blade force deviation from the nominal uniformly staggered bladerow.

On the unsteady blade force distribution, it is interesting to note that the unsteady evolution is also qualitatively different between the mis-staggered and the uniformly staggered bladerow. The blade dynamic response (phase change) can be seen from Blade 11 (Figure 16a) in contrast to Blade 12 (Figure $16 \mathrm{~b}$ ) by examining the locations of blade force peak and trough with respect to their uniform counterpart.

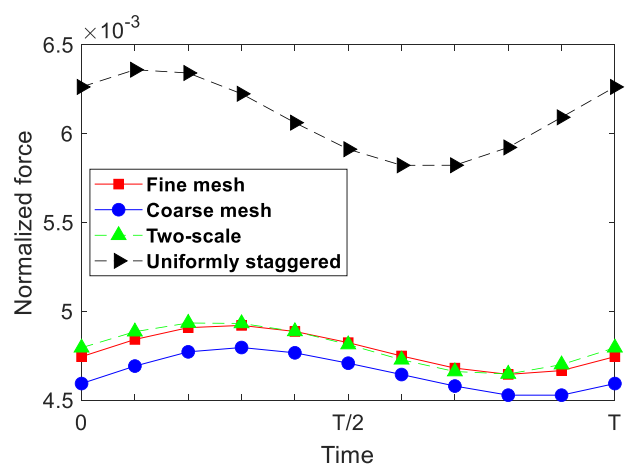

a) Blade 11

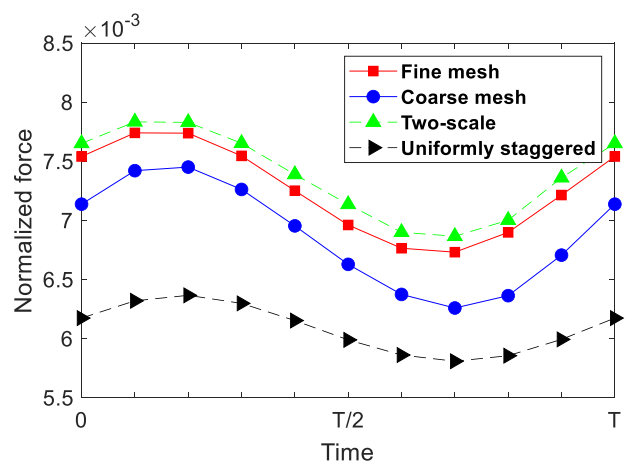

b) Blade 12

FIGURE 16: UNSTEADY LIFT FORCE EVOLUTION DURING ONE PERIOD OF INLET DISTORTION AT $k=0.5$ IN THE MISSTAGGERED BLADEROW

The comparison between the two-scale method and the direct solution again shows the highly accurate prediction capability of the two-scale method. The time-averaged and the unsteady blade force is comparable to that predicted by the direct fine mesh solution, whereas the direct coarse mesh solution is clearly lack of the quantitative agreement with the fine mesh solution. To illustrate the capability of the two-scale method on the whole flow field prediction, Figure 17 shows the instantaneous static pressure discrepancy $\Delta P$ between the coarse mesh (Figure 17a) and the two-scale method (Figure 17b) in comparison with the direct fine mesh solution.

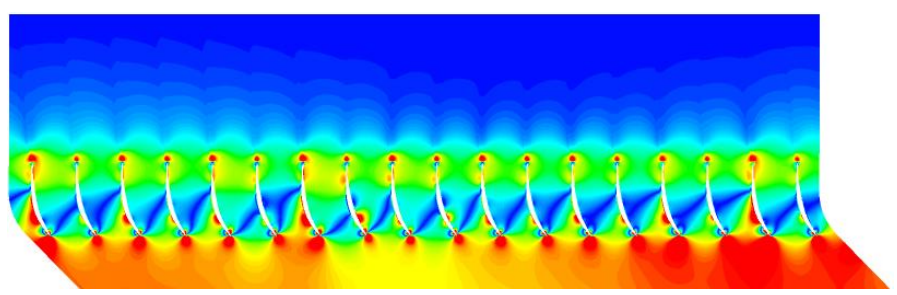

a) Difference between fine mesh and coarse mesh solution

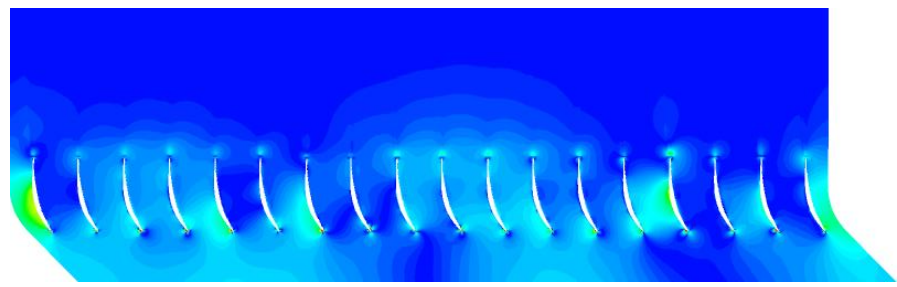

b) Difference between fine mesh and two-scale solution

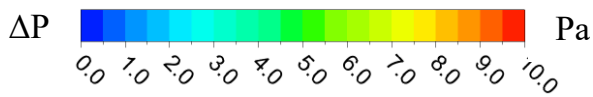

FIGURE 17: INSTANTANEOUS STATIC PRESSURE DISCREPANCY BETWEEN A DIRECT FINE MESH SOLUTION WITH: a) COARSE MESH, AND b) TWO-SCALE SOLUTION

It is clearly observed that the coarse mesh has a higher discrepancy to the fine mesh solution (Figure 17a), in agreement with the results presented in previous discussions. The majority of static pressure discrepancy clusters around the blade region as well as upstream of the bladerow. This high discrepancy reflects that the blade-to-blade aerodynamic coupling is poorly predicted in the direct coarse mesh solution. This poor prediction stems from the poorly resolved boundary layer region, then propagates upstream (where the same mesh resolution is used for all simulation setup), and then deteriorates the whole flow field prediction.

\section{Further Discussion of Computational Gain}

The objective of the proposed method is to predict the steady and unsteady flow field more accurately and more efficiently. The accuracy has been investigated in various computational examples including the uniformly staggered and the arbitrarily mis-staggered bladerow subject to clean inflow condition as well as inlet distortion. In all cases, the method has been shown to improve the quantitative prediction of the direct coarse mesh simulation. The accuracy is almost comparable to the direct fine mesh solution as if the whole annulus of the arbitrarily misstaggered bladerow is solved using a high-resolution spatial discretization.

Regarding the computational efficiency of the proposed method, it is clear that the memory and CPU time would be smaller than that used by the direct fine mesh simulation because of the reduction in mesh count used by the two-scale method. Furthermore, in the current implementation, it has also been observed that the computational saving can be potentially increased due to a faster convergence rate with the coarse mesh discretization. As a result, the total computational saving factor 
achieved is between 6 to 15 compared to the fine mesh simulation; whereas the memory saving is a factor of 3 thanks to the mesh count reduction brought in by the coarse mesh discretization.

\section{CONCLUSIONS}

Accurate and efficient modeling of a bladerow with random blade-to-blade variations subject to either clean inflow conditions or inlet distortion has always been a challenge for CFD practitioners. The current work addresses this challenge by developing an approach based on the multiscale principle in the framework of a commercial solver.

The method relies on balancing the governing equations with an appropriate spatial-temporal source term to compensate the error arisen due to spatial averaging and projection of the targeted fine mesh solution on the coarse mesh discretization. In the current framework, we propose that the source term can be a summation of the constituent source term corresponding to each flow perturbation. The source term corresponding to blade staggering is a linear superimposition of the source term from the current blade passage and from its neighbors, based on the use of Influence Coefficient Method. On the other hand, the source term corresponding to inlet distortion is related to spatial Fourier transform of the whole annulus bladerow.

The key enabler is that the source term only needs to be computed using a small training set of identical blade passages. For the staggering-dependence source term, a high-resolution five-passage configuration with the re-staggered middle blade needs to be calculated. For the inlet distortion-dependence source term, a full annulus configuration of identical blades subject to the inlet distortion has to be computed. Using the source term calculated from an identical passage configuration, the total applicable source terms are then superimposed and reconstructed at each known spatial and temporal location for any arbitrarily mis-staggered bladerow subject to inlet distortion at the expense of little extra cost. Thus, the steady and unsteady flow field of the mis-staggered bladerow subject to inlet distortion can be efficiently computed.

The summative capability of the source term is validated with the computational examples including the uniformly staggered, and the arbitrarily mis-staggered bladerows subject to either clean inflow condition or inlet distortion. The computational results of the two-scale method are in a quantitative agreement with the direct fine-mesh solution, with a clear accuracy improvement compared to the base coarse mesh simulation. The fundamental harmonic source term has been shown to be sufficient for aerodamping calculation. If one wish to include high-harmonic effects, the high harmonic source terms can be used for an improved prediction.

The results also reveal marked differences in steady and unsteady flow response between the uniformly staggered and the arbitrarily mis-staggered bladerow, thus reinforce the need to study the inlet distortion effects in the presence of the stochastic blade-to-blade variations. Some qualitative and quantitative comparisons are summarized here to highlight the effects of the mis-staggering:
1) There are $\pm 20 \%$ differences in the steady/timeaveraged blade forces between the uniformly staggered and the mis-staggered bladerow at clean inflow condition. Either a reduction or an increase in steady/time-averaged blade force can be present in the mis-staggered bladerow depending on the local stagger angle of each individual blade.

2) At a high reduced frequency of inlet distortion, the amplitude of unsteady blade force is reduced. For example, blade force unsteady amplitude decreases to $5 \%$ from $30 \%$ of the nominal value if the reduced frequency increases to 0.5 in comparison with the quasi-steady inlet distortion (at the same inlet distortion strength). In addition, the mis-staggering also induces a variation in the blade dynamic response (phase change) if the bladerow is subject to the inlet distortion.

On the computational efficiency of the two-scale method, it has been shown that the computation gain comes from the mesh reduction as well as the faster convergence rate. Consequently, the total computational saving in the current implementation of the two-scale method can be up to 15 times faster in comparison with the corresponding direct fine mesh solutions.

\section{ACKNOWLEDGMENTS}

The support from the EPSRC CDT in Gas Turbine Aerodynamics is much appreciated. The work is partly sponsored by the Chair of Computational Aerothermal Engineering Bursary. The author would like to thank $\mathrm{Mr}$. Penghao Duan for his help and fruitful discussion on the implementation aspect.

\section{REFERENCES}

[1] Erdos, J. I., Alzner, E., and McNally, W., 1977, "Numerical Simulation of Periodic Transonic Flow Through a Fan Stage,” AIAA Journal, 15(11), pp. 1559-1568.

[2] Giles, M. B., 1990, "Stator/Rotor Interaction in a Transonic Turbine," Journal of Propulsion and Power, 6(5), pp. 621-627.

[3] He, L., 1990, “An Euler Solution for Unsteady Flows Around Oscillating Blades," Journal of Turbomachinery, 112(4), pp. 714-722.

[4] Gerolymos, G. A., Michon, G. J., and Neubauer, J., 2002, “Analysis and Application of Chorochronic Periodicity in Turbomachinery Rotor/Stator Interaction Computations," Journal of Propulsion and Power, 18(6), pp. 1139-1152.

[5] He, L., and Ning, W., 1998, "Efficient Approach for Analysis of Unsteady Viscous Flows in Turbomachines,” AIAA Journal, 36(11), pp. 2005-2012.

[6] Hall, K. C., Thomas, J. P., and Clark, W. S., 2002, "Computation of Unsteady Nonlinear Flows in Cascades Using a Harmonic Balance Technique," AIAA Journal, 40(5), pp. 879-886.

[7] Vilmin, S., Lorrain, E., Hirsch, C., and Swoboda, M., 2006, "Unsteady Flow Modeling Across the Rotor/Stator Interface Using the Nonlinear Harmonic Method," Proceedings of the ASME Turbo Expo 2006: Power for Land, Sea, and Air. Volume 6: Turbomachinery, Parts A and B. Paper no. GT2006-90210.

[8] McMullen, M. S., and Jameson, A., 2006, "The Computational Efficiency of Non-Linear Frequency Domain Methods," Journal of Computational Physics, 212(2), pp. 637-661.

[9] Frey, C., Ashcroft, G., Kersken, H. P., and Voigt, C., 2014, "A Harmonic Balance Technique for Multistage Turbomachinery Applications," 
Proceedings of the ASME Turbo Expo 2014: Turbine Technical Conference and Exposition. Volume 2B: Turbomachinery. Paper no. GT2014-25230.

[10] Crespo, J., Corral, R., and Pueblas, J., 2016, "An Implicit Harmonic Balance Method in Graphics Processing Units for Oscillating Blades," Journal of Turbomachinery, 138(3), p. 031001.

[11] He, L., 2010, "Fourier Methods for Turbomachinery Applications," Progress in Aerospace Sciences, 46(8), pp. 329-341.

[12] Denton, J. D., 2010, "Some Limitations of Turbomachinery CFD," Proceedings of the ASME Turbo Expo 2010: Power for Land, Sea, and Air. Volume 7: Turbomachinery, Parts A, B, and C. Paper no. GT2010-22540.

[13] Cumpsty, N. A., 2010, "Some Lessons Learned," Journal of Turbomachinery, 132(4), p. 041018

[14] Roberts, W. B., Armin, A., Kassaseya, G., Suder, K. L., Thorp, S. A., and Strazisar, A. J., 2002, "The Effect of Variable Chord Length on Transonic Axial Rotor Performance," Journal of Turbomachinery, 124(3), pp. 351357.

[15] Montomoli, F., Massini, M., and Salvadori, S., 2011, "Geometrical Uncertainty in Turbomachinery: Tip Gap and Fillet Radius," Computers and Fluids, 46(1), pp. 362-368.

[16] Lu, Y., Green, J., Stapelfeldt S. C., and Vahdati, M., 2019, "Effect of Geometric Variability on Running Shape and Performance of a Transonic Fan," Journal of Turbomachinery, 141(10), p. 101012.

[17] Wilson, M. J., Imregun, M., and Sayma, A. I., 2006, "The Effect of Stagger Variability in Gas Turbine Fan Assemblies," Journal of Turbomachinery, 129(2), pp. 404-411.

[18] Hoyniak, D., and Fleeter, S., 1986, "The Effect of Circumferential Aerodynamic Detuning on Coupled Bending-Torsion Unstalled Supersonic Flutter," Journal of Turbomachinery, 108(2), pp. 253-260.

[19] Kaza, K. R. V., and Kielb, R. E., 1984, "Flutter of Turbofan Rotors with Mistuned Blades," AIAA Journal, 22(11), pp. 1618-1625.

[20] Sadeghi, M., and Liu, F., 2001, "Computation of Mistuning Effects on Cascade Flutter," AIAA Journal, 39(1), pp. 22-28.

[21] Ekici, K., Kielb, R. E., and Hall, K. C., 2013, "The Effect of Aerodynamic Asymmetries on Turbomachinery Flutter," Journal of Fluids and Structures, 36, pp. 1-17.

[22] Hynes, T. P., and Greitzer, E. M., 1987, “A Method for Assessing Effects of Circumferential Flow Distortion on Compressor Stability," Journal of Turbomachinery, 109(3), pp. 371-379.

[23] Longley, J. P., Shin, H. -., Plumely, R. E., Silkowski, P. D., Day, I. J., Greitzer, E. M., Tan, C. S., and Wisler, D. C., 1996, "Effects of Rotating Inlet Distortion on Multistage Compressor Stability," Journal of Turbomachinery, 118(2), pp. 181-188.

[24] Fidalgo, V. J., Hall, C. A., and Colin, Y., 2012, "A Study of Fan-Distortion Interaction Within the NASA Rotor 67 Transonic Stage," Journal of Turbomachinery, 134(5), p. 051011.

[25] Hall, D. K., Greitzer, E. M., and Tan, C. S., 2017, "Analysis of Fan Stage Conceptual Design Attributes for Boundary Layer Ingestion," Journal of Turbomachinery, 139(7), p. 071012.

[26] Provenza, A. J., Duffy, K. P., and Bakhle, M. A., 2018, "Aeromechanical Response of a Distortion-Tolerant Boundary Layer Ingesting Fan," Journal of Engineering for Gas Turbines and Power, 141(1), p. 011011.

[27] Gunn, E. J., and Hall, C. A., 2019, "Nonaxisymmetric Stator Design for Boundary Layer Ingesting Fans," Journal of Turbomachinery, 141(7), p. 071010.

[28] Li, H. D., and He, L., 2001, "Single-Passage Solution of ThreeDimensional Unsteady Flows in a Transonic Fan Rotor," Proceedings of the Institution of Mechanicak Engineers, Part A: Journal of Power and Energy, 215(6), pp. 653-662.

[29] He, L., 2006, "Fourier Modeling of Steady and Unsteady Nonaxisymmetrical Flows," Journal of Propulsion and Power, 22(1), pp. 197-201.

[30] Li, H. D., and He, L., 2008, "Single-Passage Analysis of Unsteady Flows Around Vibrating Blades of a Transonic Fan Under Inlet Distortion," Journal of Turbomachinery, 124(2), pp. 285-292.

[31] Sharma, G., Zori, L., Connell, S., and Godin, P., 2013, "Efficient Computation of Large Pitch Ratio Transonic Flow in a Fan With Inlet Distortion," Proceedings of the ASME Turbo Expo 2013: Turbine Technical Conference and Exposition. Volume 6C: Turbomachinery. Paper no. GT2013-95059.
[32] Miyakozawa, T., Kielb, R. E., and Hall, K. C., 2009, “The Effects of Aerodynamic Perturbations on Forced Response of Bladed Disks," Journal of Turbomachinery, 131(4), p. 041008.

[33] Petrov, E. P., 2010, "A Method for Forced Response Analysis of Mistuned Bladed Disks with Aerodynamic Effects Included," Journal of Engineering for Gas Turbines and Power, 132(6), p. 062502.

[34] He, L., 2013, "Fourier Spectral Modelling for Multi-Scale Aero-Thermal Analysis," International Journal of Computational Fluid Dynamics, 27(2), pp. 118-129.

[35] He, L., 2013, "Block-Spectral Mapping for Multi-Scale Solution,” Journal for Computational Physics, 250, pp. 13-26.

[36] He, L., 2018, "Multiscale Block Spectral Solution for Unsteady Flows," International Journal for Numerical Methods in Fluids, 86(10), pp. 655678.

[37] Duan, P. H., and He, L., 2019, "Application of Multi-Scale Methodology for Transonic Turbine Blade Tip Cooling Design," ASME Paper GT201991009

[38] Kapsis, M., He, L., Li, Y., Valero, O., Wells, R. G., Krishnababu, S., Gupta, G., Kapat, J., and Schaenzer, M., 2020, "Multiscale Parallelized Computational Fluid Dynamics Modeling Toward Resolving Manufacturable Roughness," Journal of Engineering for Gas Turbines and Power, 142(2), 021001.

[39] Ning, W. E. I., and He, L., 2001, "Some Modeling Issues on Trailing-Edge Vortex Shedding," AIAA Journal, 39(5), pp. 787-793.

[40] He, L., 1992, "Method of Simulating Unsteady Turbomachinery Flows with Multiple Perturbations," AIAA Journal, 30(11), pp. 2730-2735.

[41] Hanamura, Y., Tanaka, H., and Yamaguchi, K., 1980, "A Simplified Method to Measure Unsteady Forces Acting on The Vibrating Blades in Cascade," Bulletin of JSME, 23(180), pp. 880-887.

[42] Bölcs, A. and Fransson, T. H., 1986. Aeroelasticity in Turbomachines. Comparison of Theoretical and Experimental Cascade Results. Communication No.13 Lab de Thermique Appliquee, Ecole Polytechnique Federale de Lausanne (EPFL), Switzerland.

[43] Buffum, D. H., and Fleeter, S., 1990, "Oscillating Cascade Aerodynamics by an Experimental Influence Coefficient Technique," Journal of Propulsion and Power, 6(5), pp. 612-620.

[44] He, L., 1998, "Unsteady Flow in Oscillating Turbine Cascade: Part 1 Linear Cascade Experiment," Journal of Turbomachinery, 120(2), pp. 262268.

[45] He, L., 1998, "Unsteady Flow in Oscillating Turbine Cascade: Part 2 Computational Study," Journal of Turbomachinery, 120(2), pp. 269-275.

[46] Bell, D. L., and He, L., 2000, "Three-Dimensional Unsteady Flow for an Oscillating Turbine Blade and the Influence of Tip Leakage," Journal of Turbomachinery, 122(1), pp. 93-101.

[47] Huang, X., He, L., and Bell, D. L., 2008, "Effects of Tip Clearance on Aerodynamic Damping in a Linear Turbine Cascade," Journal of Propulsion and Power, 24(1), pp. 26-33.

[48] Huang, X., He, L., and Bell, D. L., 2009, "Experimental and Computational Study of Oscillating Turbine Cascade and Influence of Part-Span Shrouds," Journal of Fluids Engineering, 131(5), p.051102.

[49] Vogt, D. M., and Fransson, T. H., 2007, "Experimental Investigation of Mode Shape Sensitivity of an Oscillating Low-Pressure Turbine Cascade at Design and Off-Design Conditions," Journal of Engineering for Gas WaTurbines and Power, 129(2), pp. 530-541.

[50] Watanabe, T., Azuma, T., Uzawa, S., Himeno, T., and Inoue, C., 2018, "Unsteady Pressure Measurement on Oscillating Blade in Transonic Flow Using Fast-Response Pressure-Sensitive Paint," Journal of Turbomachinery, 140(6), p.061003.

[51] Malzacher, L., Schwarze, C., Motta, V., and Peitsch, D., 2019, "Experimental Investigation of an Aerodynamically Mistuned Oscillating Compressor Cascade," Journal of Turbomachinery, 141(7), p. 071012.

[52] Zhang, M., and He, L., 2018, "Efficient Large-Eddy Simulation Method for Blade Trailing-Edge Cooling Optimization," Journal of Propulsion and Power, 34(4), pp. 854-863.

[53] Lane, F., 1956, "System Mode Shapes in the Flutter of Compressor Blade Rows," Journal of the Aeronautical Sciences, 23(1), pp. 54-66.

[54] Barth, T., and Jespersen, D., 1989, "The Design and Application of Upwind Schemes on Unstructured Meshes," AIAA Paper no. 89-0366. 
[55] Elazar, Y., and Shreeve, R. P., 1990, "Viscous Flow in a Controlled Diffusion Compressor Cascade with Increasing Incidence," Journal of Turbomachinery, 112(2), pp. 256-265.

[56] Yang, H., and He, L., 2004, "Experimental Study on Linear Compressor Cascade with Three-Dimensional Blade Oscillation," Journal of Propulsion and Power, 20(1), pp. 108-188.

[57] He, L., and Yi, J., 2017, "Two-Scale Methodology for URANS/Large Eddy Simulation Solutions of Unsteady Turbomachinery Flows," Journal of Turbomachinery, 139(10), p. 101012.

[58] Phan, H. M., and He, L., 2019, "Validation Studies of Linear Oscillating Compressor Cascade and Use of Influence Coefficient Method," ASME Paper GT2019-90941.

[59] Menter, F. R., Langtry, R. B., Likki, S. R., Suzen, Y. B., Huang, P. G., and Völker, S., 2006, "A Correlation-Based Transition Model Using Local Variables - Part I: Model Formulation," Journal of Turbomachinery, 128(3), pp. 413-422.

[60] Plourde, G. A., and Stenning, A. H., 1968, "Attenuation of Circumferential Inlet Distortion in Multistage Axial Compressors," Journal of Aircraft, 5(3), pp. 236-242.

[61] Yao, J., Gorrell, S. E., and Waida, A. R., 2010, "High-Fidelity Numerical Analysis of Per-Rev-Type Inlet Distortion Transfer in Multistage Fans Part I: Simulations With Selected Blade Rows," Journal of Turbomachinery, 132(4), p. 041014.

\section{APPENDIX A: STEADY/TIME-AVERAGED SOURCE TERM COMPUTATION}

Consider a given time-averaged solution projected onto the coarse mesh, one can evaluate the source term explicitly using the solver numerical discretization algorithm:

$$
R(\boldsymbol{U})=\overline{\boldsymbol{U S T}}
$$

However, if the detailed discretization process is not known as typically in a commercial solver, the required source term can be evaluated using an iterative approach. The iterative procedures involve marching the solution with a pseudo time step $\Delta \tau$. The source term change at a pseudo time step $n$ is calculated as the difference between the target flow solution and the current flow solution:

$$
\Delta \overline{\boldsymbol{U S T}}_{n}=\frac{1}{\Delta \tau}\left(\overline{\boldsymbol{U}}-\overline{\boldsymbol{U}}_{n}\right)
$$

Starting from an initial value of the source term (typically given as zero for generality), the iterative procedure is repeated and a new value of the source term is updated based on the previous value and the source term change. An under-relaxation factor $\alpha$ is used to stabilize the iterative process:

$$
\overline{\boldsymbol{U S T}}_{n}=\overline{\boldsymbol{U S T}}_{n-1}+\alpha \Delta \overline{\boldsymbol{U S T}}_{n}
$$

The iteration proceeds until the source term approaches a constant value and the L2-norm of the source term change drops several orders of magnitude. Apparently when the source term iteration converges $\Delta \overline{\boldsymbol{U}} \boldsymbol{S T}_{n} \rightarrow 0$ and the current flow solution $\overline{\boldsymbol{U}}_{n}$ approaches the target time-averaged flow solution $\overline{\boldsymbol{U}}$. Thus, the projected flow solution on the coarse mesh has been recovered.

Although the above iterative process has been discuss with the time-averaged solution, a similar approach is also used to compute the steady source term by replacing the time-averaged quantities by their steady counterpart.

\section{APPENDIX B: UNSTEADY SOURCE TERM COMPUTATION}

At a physical time instant $m$, the unsteady source term comprises a time-averaged component $\overline{\boldsymbol{U S T}}$ and a fluctuating component $\boldsymbol{U} \boldsymbol{S} \boldsymbol{T}^{\prime}$ :

$$
\frac{\partial}{\partial t}\left(\boldsymbol{U}_{m}\right)+R\left(\boldsymbol{U}_{m}\right)=\overline{\boldsymbol{U S T}}+\boldsymbol{U} \boldsymbol{S} \boldsymbol{T}^{\prime}
$$

The temporal derivative is calculated using second-order backward Euler approach:

$$
\frac{\partial}{\partial t}\left(\boldsymbol{U}_{m}\right)=\frac{1}{\Delta t}\left(1.5 \boldsymbol{U}_{m}-2 \boldsymbol{U}_{m-1}+0.5 \boldsymbol{U}_{m-2}\right)
$$

where $\Delta t$ is the physical time step.

The fluctuating component of the unsteady source term is then converted from the time domain to frequency domain by Fast Fourier Transform:

$$
\boldsymbol{U S T ^ { \prime }}=\sum_{n=1}^{N f}\left(A_{\boldsymbol{U}} \cos (n \omega t)+B_{\boldsymbol{U}} \sin (n \omega t)\right)
$$

where $N_{f}$ is the number of Fourier harmonics retained; $\omega$ is the angular frequency. 